\title{
The Impact of Training Program Based on Bar-On Model of Emotional-Social Intelligence on the Development of Cognitive Flexibility among Secondary School Students in Jordan
}

\author{
Sami F. Aljazi ${ }^{1, *} \&$ Amjad F. Alrekebat ${ }^{1}$ \\ ${ }^{1}$ Curriculum and Instruction Department, Al-Hussein Bin Talal University, Ma'an, Jordan \\ *Corresponding author: Curriculum and Instruction Department, Al-Hussein Bin Talal \\ University, Ma'an, Jordan. E-mail: samialjazi@ymail.com
}

Received: February 26, 2019 Accepted: April 12, 2019 Published: April 29, 2019

doi:10.5296/ije.v11i2.14429 URL: https://doi.org/10.5296/ije.v11i2.14429

\begin{abstract}
The aim of this study was to investigate the impact of the training program based on Bar-On model of emotional-social intelligence on the development of cognitive flexibility among secondary school students in Jordan. The study sample consisted of 40 male and female students who were randomly selected. The students were equally divided into experimental group and control group. The students in the experimental and control groups completed pre-test and post-test that measure their cognitive flexibility. The students in the experimental group received emotional intelligence training that was developed based on Bar-On model of emotional-social intelligence. The training program consisted of 15 sessions. The results showed significant differences between the mean scores of the two groups in the degree of cognitive flexibility in the post-test. The students in experimental group scored higher than the students in the control group. However, there were no significant differences between the mean scores of the experimental group in the degree of cognitive flexibility in the tests based on their gender .
\end{abstract}

Keywords: Emotional Intelligence, Bar-On Model, Cognitive Flexibility 


\section{Introduction}

The study of intelligence has developed significantly over the past decades, as the attention of researchers has been shifted to understand the internal causes of the behavior that affect the adaptation of the individual. One of the main internal causes of the behavior is the degree of intelligence. The current definitions of intelligence focused on the one's multiple abilities that are associated with several types of intelligence rather than focusing on the one's general mental ability that contribute to his/ her success in life

Emotional intelligence is one of the most widely studied types of intelligence. Such high interest of studying emotional intelligence was due to the change in the traditional view of intelligence. Such interest of studying emotional intelligence was evident in Goleman's (2000) work, who wrote a book under the title "Emotional Intelligence", as well as the efforts of Salovey and Mayer (1990), who preceded him to address the emotional intelligence issue on a narrower scale in 1990 (Al-Kader, 2006).

The definition of emotional intelligence was influenced by the early definitions of social intelligence. Some researchers believed that emotional intelligence is part of social intelligence since the two concepts were highly related (Salovey \& Mayer, 1990). Gardner (1983) described emotional intelligence as the inner side of personal intelligence, while social intelligence represents the external aspect of it.

The research studies that were conducted in Arabic language have used different terms for emotional intelligence such as affection intelligence, psychological intelligence, and intelligence of feelings. This difference is due to the difference in translation as well as the attempt to associate emotional intelligence concept with good experiences or unpleasant experiences (Hussein \& Hussein, 2006).

There are several definitions of emotional intelligence. For instance, Goleman (2000) defined emotional intelligence as the individual's emotional, social and personal skills necessary for success in life. Bar-Onand Parker (2000) defined emotional intelligence as individual's capacity associated with self-understanding and understanding of others as well as the ability to adapt to the environment and to manage emotions. These definitions showed that the emotional intelligence is related to the individual's ability to recognize his/her emotions and emotions of others as well as to positively direct these emotions which contributes in establishing a friendly relationship with others. The interest in studying emotional intelligence was accompanied with the emergence of a number of models that provided different interpretations of emotional intelligence based on different theoretical foundations. The most prominent examples of these models are the Goleman's (1996) model, Salovey \& Mayer's (1990) model and the Bar-On's (2006) model.

Bar-On's (2006) model addressed the concept of emotional intelligence by focusing on its effects and outcomes through combining the analysis of personality traits and emotions in its social context. Bar-On's (2006) model described emotional intelligence as a set of non-cognitive mental abilities and skills that affect an individual's ability to adapt to environmental requirements and pressures (Bar-On, 2006). 
Bar-On (2006) identified five abilities or skills of emotional intelligence, these abilities or skills were:

Intrapersonal competencies and emotional skills: That can be defined as the group of abilities and skills that help the individual to understand and deal with his / her emotions successfully such as self-awareness, self- assertiveness, self-esteem, self- actualization, and independence.

Interpersonal competencies and social skills: That can be defined as the group of abilities and skills that help the individual to establish successful relationships and have a positive impact on others such as: empathy, social responsibility, and interpersonal relationship.

Adaptability competencies and skills: That can be defined as the group of abilities and skills that help the individual to successfully adapt to external reality and the requirements of the surrounding environment, such as problem solving, reality testing and flexibility

Stress management competencies and skills: That can be defined as the group of abilities and skills that help the individual to effectively manage stress, resist rush and to control emotions, such as impulse control and stress tolerance.

General mood competencies and skills: That can be defined as the group of abilities and skills that help the individual to manage the mood and change it positively, such as happiness and optimism.

The Bar-On's (2006) model showed that there were close relationship between emotional intelligence and many aspects of human performance such as school performance, mental health and social interactions. The model pointed to the possibility of improving the performance of individuals by teaching them emotional intelligence skills. Acquiring emotional intelligence skills would contribute in improving emotional self-awareness and self-expression (Freedman, 2003).

Cognitive flexibility plays integral role in activating and modifying individual's cognitive processes that would help in handling different life situations, selecting and controlling the right behavioral strategies that fit real-life context, and making the required adjustment to the life situations (Deak \& Wiseheart, 2015). Yazdi, Farahi, Farahi, and Hosseini, (2018) conducted a study that aimed to examine the effect of emotional intelligence on cognitive flexibility of children with Attention Deficit Hyperactivity Disorder (ADHD). Fifty male children participated in the study, 20 children with ADHD and 30 normal children. The results showed that the emotional intelligence can be used as predictor of cognitive flexibility in thetwo groups. In addition, the results showed that children with ADHD had lower performance than normal children in emotional intelligence and cognitive flexibility measures.

Deak (2003) defined cognitive flexibility as the one's ability to construct new cognitive representations or to modify previous cognitive representations and generate new responses to situations and events. Andersson (2002) focused on the relationship between one's cognitive flexibility and his/her ability to adapt to situations that require problem-solving skills and ability to consider variety of ideas and different views. Gunduz (2013) presented a 
definition of cognitive flexibility as "adjusting to specific situations, the ability to pass from one idea to another idea or the capacity to consider various problems in terms of multi-dimensions" (p. 2079). Such definition aligned with Hilal's (2015) definition of cognitive flexibility as the ability to navigate between responses and tasks within different contexts taking into account the contradictions.

The previous definitions of cognitive flexibility showed that cognitive flexibility reflect the individual's ability to adapt to different situations through the use of different strategies for each situation and selection of appropriate strategies and alternatives without holding to specific ones. Cognitive flexibility is an important dimension of one's personality since it has a role in facilitating adaptation to new situations, improving social interaction, enhancing acceptance to different ideas and promoting the use of diverse cognitive strategies (Bilgan, 2009). Cognitive flexibility contributes in changing the cognitive strategies that an individual employs to deal with new situations and to find appropriate solutions to real-life problems.

Cognitive flexibility can be divided into two dimensions: The first one is adaptive flexibility that relates to the one's ability to change his/her thinking methods according to the situation in an unconventional way. The second dimension is spontaneous flexibility that relates to the one's ability to produce and generate ideas and move smoothly from one idea to another (Cartwright, 2008). Cognitive flexibility allows an individual to change his/her perceptions of situations and of external reality, to create new relationships between different elements of external reality, to rearrange these elements according to their importance in different contexts, and to reconstruct and develop his/her knowledge spontaneously (Cañas, Antolí, Fajardo, \& Salmerón, 2005). In addition, cognitive flexibility has a role in improving individual's attention, awareness and social interaction by providing cognitive mechanisms that help him/her to adapt to new stimuli and variables (Malachowski, Martin, \& Vallade, 2013). Sa'adeh (2003) pointed to the possibility of developing cognitive flexibility skills through training, such training would focus on developing students' viewpoints of different situations and developing their ways of thinking in order to make them understand external reality in different ways rather than in the ordinary way.

\subsection{Problem of the Study}

Building and developing students' cognitive flexibility has become an important requirement for many personal, social and educational reasons. Cognitive flexibility has crucial and active role in helping individual to adapt to, deal with, and respond to the new situations in real life. Training can be considered as a possible way to develop students' cognitive flexibility skills. Cognitive flexibility training can be used to enhance students' problem-solving skills and their flexibility in thinking. Therefore, there is a need to examine the impact of training program based emotional intelligence skills and competencies on the development of cognitive flexibility. The main research question in this study is: What is the impact of training program based on Bar-On model of emotional-social intelligence on the development of cognitive flexibility among secondary school students in Jordan? 
1.2 Research Questions

- Are there any statistically significant differences $(\alpha \leq 0.05)$ in mean scores on the measure of cognitive flexibility for the students in the experimental group and in the students in control group due to the use of training program based on Bar-On model of emotional-social intelligence?

- Are there any statistically significant differences $(\alpha \leq 0.05)$ in mean scores on the measure of cognitive flexibility for the students based on their gender?

\subsection{Purpose of the Study}

This study aimed to improve the degree of cognitive flexibility for group of students by building a training program based on the Bar-On model of emotional-social intelligence.

\subsection{Importance of the Study}

This study has theoretical and practical significance. The theoretical significance lies in providing and adding to the knowledge and information about the Bar-On model of emotional-social intelligence and the impact of employing training program based on this model on the development of cognitive flexibility.

The practical significance lies in providing psychologists and educators with a training program that can be used to improve students' cognitive flexibility. This study is one of a few studies that discussed the development of training program to improve students' cognitive flexibility.

\subsection{Limitations of the Study}

This study was conducted within the following limitations:

- Only students in the secondary level participated in the present study.

- The study was conducted in the academic year 2018/2019.

- Limitations associated with the used training program, the used cognitive flexibility measure and their psychometric characteristics.

\subsection{Study Terms}

- The training program: group of activities and organized experiences that were developed based on the Bar-On model of emotional-social intelligence. The training program included training sessions that were developed by the researchers. The students completed the training program in order to develop their cognitive flexibility.

- Emotional intelligence: abilities and skills associated with self-understanding and understanding of others and the ability to adapt to the environment and manage emotions (Bar-On\& Parker, 2000).

- Cognitive flexibility: the ability of the individual to adapt to situations that require problem-solving skills, to shift thinking between two components of a set of stimuli, and to consider different views (Anderson, 2002). The operations definition of cognitive flexibility 
is the degree to which the respondent receives at the Abdulwahab's scale (2011).

\section{Previous Studies}

The following is a presentation of some of previous studies that examined level of emotional intelligence, cognitive flexibility, and some other variables among different groups of people. The previous studies helped in preparing and implementing the training program in this study .

\subsection{First: Studies That Discussed Emotional Intelligence Programs}

Lang (2018) conducted a study that aimed to identify the impact of an emotional intelligence training program on improving emotional regulation among bullying students. The study sample consisted of 40 students who were equally divided into experimental group and control group. Pre-test and post-test were administrated to the experimental and control groups, the tests were designed to evaluate regulated negative emotion and perceived empathy. The participants in the experimental group completed an emotional intelligence training program that lasted for five weeks. The results showed that there was improvement in students' regulated negative emotion and perceived empathy in the experimental group as result of the application of the emotional intelligence training program.

Al-Zyadat and Jebreel (2015) conducted a study that aimed to examine the efficiency of a training program based on emotional intelligence in improving life satisfaction among substance abusers. The study sample consisted of 30 participants who were divided into experimental group and control group. The participants in experimental and control groups completed a measure of life satisfaction before and after completing training program based on emotional intelligence that was directed for the students in the experimental group. The results showed that the training program based on emotional intelligence was efficient in improving life satisfaction among participants .

Hamadneh (2014) investigated the efficacy of training program based Goleman emotional intelligence theory in improving creative thinking skills of school students. The sample for the study consisted of 80 students, who assigned into two groups, the experimental group $(n=40)$ and control group $(n=40)$. Torrance Tests of Creative Thinking form was used as pre-test and post-test. The results showed that there was significant difference in students' level of creative thinking skills in favors to the experimental group. However, the results showed that there were no significant differences in participants' level creative thinking skills based on their gender and age .

Ruiz-Aranda, et al. (2012) investigated the efficacy of an emotional intelligence education program based on Mayer and Salovey's (1997) model on the level psychosocial adjustment for a group of Spanish adolescents. The sample of the study consisted of 147 high school students, who were assigned into two groups, the experimental group $(n=78)$ and control group $(n=69)$. The results showed that the students who participated in the emotional intelligence education program reported improved psychosocial adjustment such as lower levels of depression and anxiety and higher self-esteem compared to students in the control 
group.

Yilmaz (2009) conducted a study that aimed at identifying the impact of emotional intelligence skill training program on in the level of consistent anger among university students. The sample of the study consisted of 32 university students, who were assigned into two groups, the experimental group $(n=16)$ and control group $(n=16)$. The participants in experimental and control groups completed consistent anger test before and after completing emotional intelligence skill training program that was directed for the students in the experimental group. The results showed that that the level of consistent anger of those who attended the emotional intelligence skill training program was lower than for those who did not attend this program .

\subsection{Second: Studies That Discussed Cognitive Flexibility}

Safiya and Al-Zghoul (2017) conducted a study that aimed to investigate the impact competency in the second language on working memory and cognitive flexibility of bilingual students. The study sample consisted of 274 bilingual school students. The results of the study showed that the levels of both working memory capacity and cognitive flexibility were high. In addition, there were statistically significant differences in the levels of both working memory capacity and cognitive flexibility based on the competency in the second language.

Waheed (2017) conducted a study that aimed to identify the mastery motivation and its relation to the cognitive flexibility among university students. The study sample consisted of 300 male and female students. A questionnaire that consisted of mastery motivation scale and Fadhil's (2015) cognitive flexibility scale was administrated. The results showed a direct correlation between mastery motivation and cognitive flexibility. In addition, the results showed that there were no significant differences in participants' degree of cognitive flexibility based on their gender.

Al-Orsan (2017) conducted study that aimed to identify the effectiveness of the use of active learning strategies in the development of cognitive flexibility and academic achievement motivation among university students. The study sample consisted of (65) students divided into two groups: experimental group $(n=33)$ and control group $(n=32)$. The participants completed a questionnaire that consisted of two scales: cognitive flexibility scale and academic achievement motivation scale. The results showed that there were statistically significant differences between students' levels of cognitive flexibility and academic achievement motivation in favor of experimental group due to the use of active learning strategies.

In order to identify the need for cognition and its relation to cognitive flexibility in thinking among high school students, Sawaed (2016) conducted a study in which 218 school students completed a questionnaire that had two scales: need for cognition scale and cognitive flexibility scale. The results revealed high levels of need for cognition and knowledge flexibility among the sample members. There was a positive correlation between the need for cognition and cognitive flexibility among participants. In addition, the results showed that there were no significant differences in participants' degrees of need for cognition and cognitive flexibility based on their gender.

Kader (2008) conducted a study that aimed to develop cognitive flexibility and to examine 
the effect of cognitive flexibility on the acquisition of concepts among students at the faculty of educational science. The sample of the study consisted of 85 university students, who assigned into two groups, the experimental group and control group. The participants completed cognitive flexibility questionnaire and test of acquisition of concepts. The results showed that there were statistically significant differences on both scales for the benefit of the experimental group in which the students received training through the high-text system based on the theory of cognitive flexibility.

Cañas, Antolí, Fajardo, and Salmerón (2005) investigated the effect of different types of training on the development of cognitive flexibility and problem-solving strategies. The study sample consisted of 80 male and female students. The students were divided equally into two groups. The first group was trained with constant training condition. The second group was trained with variable training condition. Cognitive flexibility was examined through measuring the number of problem-solving strategies. The results showed that the pattern of training had impact on cognitive flexibility, where students who had been trained with variable training condition had higher cognitive flexibility.

\subsection{Comments on Previous Studies}

The presentation of previous studies showed diversity of studies that examined emotional intelligence and the association between emotional intelligence and other variables. However, there was no study that examined the use of emotional intelligence training program based on the Bar-On model. Therefore, the significance of this study lies in the development and use of training program based on Bar-On model of emotional-social intelligence and examining its effect on the development of cognitive flexibility for students. The current study would provide stimulating training program for students to learn in schools. This type of training would increase students' role in learning, make them more active, and change their roles from absorber of knowledge to producers of knowledge.

\section{Methodology and Research Design}

\subsection{Study Sample}

The study sample consisted of 40 secondary school students. The students were selected from the southern Badia schools. The selected students were undergoing a training course at training center called the Future Center for Education and Development. The participants were randomly selected using simple random sampling method. However, gender representation was considered in the selection process. The students were divided into two groups: experimental group and control group. Only students in the experimental group completed the training program based on Bar-On model of emotional-social intelligence. Pre-test and post-test were administrated to the experimental and control groups, the tests were designed to evaluate participants' levels of cognitive flexibility.

\subsection{Study tool}

In order to examine the impact of training program based emotional intelligence on the 
development of cognitive flexibility among secondary school students, Abdulwahab's scale (2011) was used to measure students' cognitive flexibility. Abdulwahab's scale consisted of 30 positively worded items.

The validity of the used instrument, that measured students' levels of cognitive flexibility, was verified by asking a panel of experts to review the instrument. The panel of expert consisted of seven faculty members who have been working at the Jordanian universities and they have doctorate degrees different educational disciplines that include educational psychology and educational measurement and evaluation. These reviewers reviewed the language of the instrument's items and the extent to which each item accurately measures what it is supposed to measure. In addition, the reviewers rated each item based on its relevance to the cognitive flexibility scale. The researchers reviewed the instrument according to the experts' notes.

Test-retest reliability was used to check the used instrument's consistency among two administrations, one month apart. In addition, Cronbach's alpha for the scale was calculated. Twenty male and female students, who were not part of the study, completed the Abdulwahab's scale. The test-retest reliability coefficient was 0.84 . The value of Cronbach's alpha was 0.73 . The values of test-retest reliability coefficient and Cronbach's alpha were accepted for the purpose of the study. Furthermore, correlation coefficients were used to determine the degree to which each item in the cognitive flexibility scale was associated with the related subscale. The correlation coefficients ranged from 0.33 to 0.79 , the mean value of correlation coefficients was 0.56 . The results indicated that each item in the scale was satisfactorily associated with the scale.

\subsubsection{The levels of the cognitive flexibility scale}

This study was self-report study, where the participants read the scale's items and selected a response by themselves without researchers' interference. The cognitive flexibility scale consisted of 30, three-point Likert-type items. The three possible responses were $3=$ completely apply, $2=$ apply, $1=$ Not sure. The total score of the scale ranged from 30 to 90 , the higher the score the higher the respondent's level of cognitive flexibility.

\subsection{Variables of the Study}

The independent variables were the group and gender. The group variable has two levels, the experimental group and control group. The gender variable has two options, male and female. The dependent variable was participants' level of cognitive flexibility.

\subsection{The Training Program}

In order to accomplish the goal of the study, a training program based on Bar-On model of emotional-social intelligence was developed. The development of the training program was developed after examining multiple emotional intelligence models, formulating the goals of the program and identifying appropriate activities. The training program consisted of different training situations and activities that were appropriate to the objectives of the program and age of the trainees. The developed training program was reviewed by a panel of experts. The panel of expert consisted of four faculty members who have been working at the 
Jordanian universities. The experts' comments were used to improve the training program in order to accomplish its goal of providing the trainees with emotional intelligence skills based on Bar-On model. The training program had the following assumptions:

- Emotional intelligence deals with mental abilities and non-cognitive emotional abilities.

- Bar-On model of emotional-social intelligence includes personal, emotional and social skills and competencies.

- An individual's ability to adapt to environmental requirements and pressures is affected by a range of non-cognitive abilities and skills.

- Bar-On identified the characteristics of emotional intelligence based on the abilities associated with emotional and social knowledge that affect the overall ability to effectively address the requirements of the environment.

- Bar-On assumes that emotional intelligence consists of five non-cognitive skills or abilities: internal personal components, interpersonal relationship components, adaptability components, stress management components, and general mood components.

The program consisted of 15 training sessions; each session was 45 minutes long. The training program adopted several educational strategies that include: dialogue and discussion strategy, working in groups, modeling, brainstorming, self-questioning, and educational scaffolding.

The students in the experimental and control groups completed the instrument before and after the training program in order to examine the effectiveness of the program in the development of cognitive flexibility among secondary school students.

The training sessions dealt with the following Bar-Onskill for of emotional-social intelligence:

- Intrapersonal competencies and emotional skills that include: self-awareness, selfassertiveness, self-esteem, self- actualization, and independence.

- Interpersonal competencies and social skills that include: empathy, social responsibility and interpersonal relationship.

- Adaptability competencies and skills that include: problem solving, reality testing and flexibility

- Stress management competencies and skills that include: bearing pressure, tension, and impulse control.

- General mood competencies and skills that include: happiness and optimism.

\subsection{Research Design}

Survey and pre-post experimental study design was used to guide this study. The participants were assigned to either a control group or an experimental group. Before the training intervention, questionnaires were used to collect data from the students in the control and experimental groups regarding their perceptions of their levels of cognitive flexibility. Then, the 
students in the experimental group received training based on Bar-On model of emotional-social intelligence. After the completion of training program, questionnaires were re-administrated to collect data from the students in the control and experimental groups regarding their perceptions of their levels of cognitive flexibility. Table 1 shows the study design.

Table 1. The Research Design

\begin{tabular}{llll}
\hline Experimental group & $\mathrm{O} 1$ & $\mathrm{X}$ & $\mathrm{O} 2$ \\
\hline Control group & $\mathrm{O} 1$ & & $\mathrm{O} 2$ \\
\hline
\end{tabular}

$\mathrm{X}=$ The training program, $\mathrm{O}=$ Pre-test and post-test

\subsection{Research Procedure}

The used procedure of the study can be summarized in the following steps:

1. Designing the training sessions based on the examined theoretical framework and the previous studies in order to train the students on how to employ emotional intelligence skills in real life situations.

2. Developing the training sessions by the researchers. Each training session consisted of group of training activities associated with a particular emotional intelligence skill. The training was delivered using variety of educational strategies.

3. Questionnaires were used to collect data from the students in the control and experimental groups regarding their perceptions of their levels of cognitive flexibility. Students' responses to the questioners were properly coded.

4. The students were divided into two groups: experimental group and the control group.

5. Carrying out the training sessions for the students in the experimental group. The program consisted of 15 training sessions; each session was 45 minutes long. The training lasted for five weeks, three sessions a week.

6. After the completion of training program, questionnaires were re-administrated to collect data from the students in the control and experimental groups regarding their perceptions of their levels of cognitive flexibility.

7. Data were statistically analyzed and the results were presented and interpreted in light of the theoretical framework and previous studies

\section{Results and Discussions}

\subsection{Results Related to the First Research Question}

The first research question stated that:: Are there any statistically significant differences $(\alpha \leq$ 0.05 ) in mean scores on the measure of cognitive flexibility for the students in the 
experimental group and in the students in control group due to the use of training program based on Bar-On model of emotional-social intelligence?

In order to answer the first research question, means and standard deviations of the participants' responses to the cognitive flexibility scale, before and after the training program, were computed. Table 2 shows the means and standard deviations for the participants' responses to cognitive flexibility scale in the pre-tests and post-tests

Table 2. The Means and Standard Deviations for the Participants' Responses to Cognitive Flexibility Scale in the Pre-Tests and Post-Tests

\begin{tabular}{llllll}
\hline Groups & $\mathrm{n}$ & \multicolumn{2}{c}{ Pre-test } & \multicolumn{2}{c}{ Post-test } \\
\cline { 3 - 6 } & & $\mathrm{M}$ & $\mathrm{SD}$ & $\mathrm{M}$ & $\mathrm{SD}$ \\
\hline Experimental group & 20 & 67.10 & 11.17 & 74.05 & 6113. \\
Control group & 20 & 66.72 & 11.80 & 66.95 & 1212. \\
Total & 40 & 66.91 & 11.49 & 70.50 & 12.87 \\
\hline
\end{tabular}

Table 2 shows that there were differences between the mean scores of the cognitive flexibility post-test for the students in the experimental group and the students in the control group. The mean score of the cognitive flexibility post-test for the students in the experimental group was (74.05), where that was higher than the mean score for the students in the control group who scored (66.95).

In order to check for the significance of the difference between mean scores between the two groups, Analysis of Covariance (ANCOVA) was conducted. ANCOVA evaluated whether the means of students' score in the post-test (independent variable) were equal for the students in the experimental and control groups (dependent variables), while statistically controlling for the effects of pre-test scores (covariate). Table 3 shows the ANCOVA summary.

Table 3. ANCOVA Summary Table for Post-test Cognitive Flexibility Scores for the Students in the Experimental and Control Groups by Training Program with Pre-test as Covariates

\begin{tabular}{cccccc}
\hline Source & $\begin{array}{c}\text { Sum of } \\
\text { Squares }\end{array}$ & $\begin{array}{c}\text { Degree of } \\
\text { freedom }\end{array}$ & Mean Square & F & Sig. \\
\hline Pre-test & 127.084 & $\mathbf{1}$ & 127.084 & .760 & .389 \\
Group & 1571.364 & 1 & 1571.364 & $\mathbf{9 . 3 9 8}$ & .004 \\
Error & 6186.416 & 37 & 167.200 & & \\
Total & 7801.900 & 39 & & & \\
\hline
\end{tabular}

Table 3 presents the analysis of covariance of participants' levels of cognitive flexibility by the training program. The table reveals a significant effect of training program on participants' levels of cognitive flexibility $(\mathrm{F}(1,37=9.398), \mathrm{P}<0.05)$. The adjusted value of the mean 
score of the cognitive flexibility post-test for the students in the experimental group was (74.26), which was higher than the adjusted value of the mean score of the cognitive flexibility post-test for the students in the control group that was (67.19). The difference between the adjusted values of the group means in the post-tests was (7.07). Table 4 shows the adjusted values of the group means and the standard errors of two groups for the post test scores.

Table 4. Shows the Adjusted Values of the Group Means and the Standard Errors for the Post Test Scores

\begin{tabular}{cccc}
\hline Group & $\mathrm{N}$ & Mean & Standard error \\
\hline Experimental & 20 & 74.26 & .9022 \\
Control & 20 & 67.19 & .9022 \\
\hline
\end{tabular}

The results show that there were improvements in the post-test mean scores on the cognitive flexibility scale for the students in the experimental group. That indicates that the training program based on Bar-On model of emotional-social intelligence was useful and effective in improving students' cognitive flexibility. The positive effect of the training program can be attributed to the provided emotional intelligence skills. The emotional intelligence skills contributed in building an organized and flexible knowledge for the trainees. Such flexible knowledge enabled the trainees to recognize their abilities and to use these abilities in adapting to different situations and that contributed in changing their ways of thinking within their social contexts.

The result related to the effectiveness of the training program based emotional intelligence on improving students' cognitive flexibility aligned with Bar-On's propositions that there were strong association of emotional intelligence with many aspects of human performance and social interactions; and there was possibility of improving the individuals' performance by teaching emotional intelligence skills. In addition, the result related to the effectiveness of the training program aligned with Sa'adeh's (2003) suggestions that there was possibility of developing and improving cognitive flexibility skills through training that focus on allowing the students to examine different viewpoints and trying to vary their way of thinking and perceptions of the life situations and matters.

Furthermore, the finding related to the effectiveness of the training program on improving students' cognitive flexibility aligned with some studies that showed the effectiveness of training program that were developed based on emotional intelligence. The finding aligned with the different research studies such as Lang, (2018); Al-Zyadat and Jebreel, (2015); Hamadneh, (2014), Ruiz-Aranda, et al., (2012); Yilmaz (2009). These studies showed that there was positive role of training programs based on emotional intelligence in the development of students' psychological and social skills and performances. 


\subsection{Results Related to the Second Research Question}

The second research question stated that: Are there any statistically significant differences $(\alpha$ $\leq 0.05$ ) in mean scores on the measure of cognitive flexibility for the students based on their gender?

In order to answer the second research question, independent sample t-tests were carried out to examine variations in the levels of cognitive flexibility in the post-test for the students in the experimental group according to their gender. Table 5 shows the results of t-tests for students' perceptions of their levels of cognitive flexibility based on their gender.

Table 5. Descriptive Statistics and Results of T-Tests for Students' Perceptions of Their Levels of Cognitive Flexibility Based on Their Gender

\begin{tabular}{ccccc}
\hline Gender & Mean & SD & t & Sig \\
\hline Male & 70.30 & 15.07 & 1.052 & .270 \\
Female & 65.60 & 13.10 & & \\
\hline
\end{tabular}

Table 5 shows that there were no significant differences at $(\alpha<0.05)$ between the means of the responses of the students in the experimental group to cognitive flexibility scale after receiving emotional intelligence training, $\mathrm{t}(38)=1.052, \mathrm{p}=.270$ based on their gender.

Such results aligned with definitions of cognitive flexibility presented by Deak (2003) who reported that cognitive flexibility is associated with one's ability to construct new cognitive representations or to modify previous cognitive representations and generate new responses to situations and events. In addition, the results aligned with definitions of cognitive flexibility presented by Anderson (2002) who focused on the relationship between one's cognitive flexibility and his/her ability to adapt to situations that require problem-solving skills and ability to consider variety of ideas and different views. Such definitions showed that cognitive flexibility is related to the individual's personal experiences and social interaction, regardless of his/her gender.

The insignificant differences in students' level of cognitive flexibility based on their gender might be attributed to the appropriateness of the training program and training activities to the female and male students. The training program provided equal opportunity for the male and female students. In addition, the training program provided the same social context and similar training conditions for the trainees regardless of their gender.

The result related to the insignificant differences in students' level of cognitive flexibility based on their gender aligned with the finding of the studies conducted by Waheed (2017) and Sawaed (2016). Furthermore, the insignificant differences in students' level of cognitive flexibility based on their gender might be related to the fact that interaction with the surrounding events and stimul and the nature of psychological construction are related to the individuals' abilities and tendencies. Such abilities and tendencies vary between individuals regardless of their gender. 


\section{Recommendations}

In light of the findings of the study, the researchers recommended the following:

1. Professionals and educational practitioners should pay attentions to the practical applications of the Bar-On model of emotional-social intelligence. They should enrich the educational curricula with activities based on this model.

2. Professionals and educational practitioners should design and develop training programs that aim to develop students' levels of cognitive flexibility and link cognitive flexibility to different aspects of thinking.

3. Professionals and educational practitioners should pay attentions to the development of educational environments that focus on different types of intelligence, including emotional and social intelligence.

\section{References}

Abdulwahab, S. (2011). Cognitive flexibility and its relation to both the perspective of the future and the goals of achievement university faculty members. Research Journal Specific Education, 20. Retrieved from http://kenanaonline.com/files/0096/96611/02.pdf [Arabic]

Al-Kader, O. (2006). Emotional Intelligence: Rephrasing the concept of intelligence. Kuwait: Intellectual Creation Company for Publishing and Distribution. [Arabic]

Al-Orsan, S. (2017). The Effectiveness of Using Active Learning Strategies Based on Social Cognitive Theory in Developing Cognitive Flexibility and Academic Achievement Motivation among Students of Psychology at the University of Hail. Journal of Al-Quds Open University for Educational and Psychological Research and Studies, 5(9), 123-142. [Arabic]

Al-Zyadat, M., \& Jebreel, M. (2015). The efficacy of a training program based on emotional intelligence in improving life satisfaction among substance abusers. Dirasat: Educational Sciences, 42(2), 533-547. https://doi.org/10.12816/0017384 [Arabic]

Anderson, P. (2002). Assessment and development of executive function (EF) during childhood. Child Neurophysiology, 8(2), 71-83. https://doi.org/10.1076/chin.8.2.71.8724

Bar-On, R., \& Parker, J. (2000). The Bar-On Emotional Quotient Inventory: youth version (EQ-i:YV) technical manual. Toronto, Canada: Multi-Health Systems, Inc.

Bar-On, R. (2006). The Bar-On model of emotional-social intelligence (ESI). Article Retrieved August 21, 2018, from http://www.eiconsortium.org

Bilgin, M. (2009). Developing a cognitive flexibility scale: validity and reliability studies. Social behavior and personality, 37(3), 343-354. https://doi.org/10.2224/sbp.2009.37.3.343

Cañas*, J. J., Antolí, A., Fajardo, I., \& Salmerón, L. (2005). Cognitive inflexibility and the development and use of strategies for solving complex dynamic problems: effects of different types of training. Theoretical Issues in Ergonomics Science, 6(1), 95-108. 
https://doi.org/10.1080/14639220512331311599

Cartwright, K. (2008). Literacy processes: Cognitive flexibility in learning and teaching. New York: Guilford publishing.

Deak, G. (2003). The Development of Cognitive Flexibility and language abilities. In R. V. Kail (Ed.), Advances in child development and behavior, 31, 271-327. San Diego, CA, US: Academic Press.

Deak, G., \& Wiseheart, M. (2015). Cognitive Flexibility in young children: General or task-specific capacity. Journal of Experimental Child Psychology, 138, 31-53. https://doi.org/10.1016/j.jecp.2015.04.003

Fadhil, B. (2015). Creative awareness, innovation motivation and knowledge resilience for creative and non-creative students at the preparatory stage (comparative study). (Unpublished doctoral dissertation). College of Education, Abn Rashid. Baghdad, Iraq [Arabic]

Freedman, J. (2003). Key lessons from 35 years of social-emotional education: how self-science builds self-awareness, positive relationships and decision-making. Perspectives in Education, 21, 69-80.

Gardner, H. (1983). Frames of mind. New York: Basic Books.

Goleman, D. (1996). Emotional intelligence. Why it can matter more than IQ. Learning, 24(6), 49-50.

Goleman, D. (2000). Working with Emotional Intelligence and Emotional Intelligence. Bantam: Reprint edition

Gunduz, B. (2013). The Contributions of Attachment Styles, Irrational Beliefs and Psychological Symptoms to the Prediction of Cognitive Flexibility. Educational Consultancy and Research Centre, 13(4), 2079-2085.

Hamadneh, B. (2014). The efficacy of a training program based on Goleman emotional intelligence theory to develop creative thinking skills Among sample of Jordanian gifted students. Arab Journal for Talent Development, 5(9), 123-142. [Arabic]

Hilal, A., (2015). Modeling casual relationship among involuntary memories, cognitive flexibility and episodic future thinking in university students. Journal of Counseling, 44, 1-49. [Arabic]

Hussein, S., \& Hussein, T., (2006). Emotional intelligence for educational leadership. Amman: Dar al Fikr for Publishing \& Distributing. [Arabic]

Kader, A. (2008). Developing cognitive flexibility effect on the acquisition of concepts among a sample of educational sciences faculty. Unpublished doctoral dissertation, Yarmouk University, Jordan. [Arabic]

Lang J. (2018). The Efficacy of Emotional Intelligence Training for the Emotion Regulation of Bullying Students: A Randomized Controlled Trial. NeuroQuantology, 16(2), 83-88. https://doi.org/10.14704/nq.2018.16.2.1176

Malachowski, C., Martin, M., \& Vallade, J. (2013). An Examination of Students' Adaptation, Aggression, and Apprehension Traits with Their Instructional Feedback Orientations. Communication

Education,

$62(2)$

127-147. 
https://doi.org/10.1080/03634523.2012.748208

Mayer, J. D., \& Salovey, P. (1997). What is emotional intelligence? In P. Salovey \& D. J. Sluyter (Eds.), Emotional development and emotional intelligence: Implications for educators (pp. 3-31). New York: Basic Books.

Ruiz-Aranda, D., Salguero, J., Cabello, R., Palomera, R., \& Fernández-Berrocal, P. (2012). Can an emotional intelligence program improve adolescents' psychosocial adjustment? Results from the INTEMO project. Social Behavior and Personality: An international journal, 40, 1373-1380. https://doi.org/10.2224/sbp.2012.40.8.1373

Sa'adeh, G. (2003). Teaching Thinking Skills. Amman: Dar Al Shorouk Publishing \& Distribution. [Arabic]

Safiya, M., \& Al-Zghoul, R. (2017). The Effect of Competency in the Second Language on Working Memory and Cognitive Flexibility among Bilingual Students in Akko City. An-Najah University Journal for Research. 31(9), 1489- 1524. [Arabic]

Salovey, P., \& Mayer, J. (1990). Emotional intelligence. Imagination, Cognition and Personality, 9, 185-211. https://doi.org/10.2190/DUGG-P24E-52WK-6CDG

Sawaed, M. (2016). The need for cognition and its relationship to cognitive flexibility in thinking among secondary stage students in Upper Galilee. Unpublished master dissertation, Amman Arab University, Jordan. [Arabic]

Waheed, M. (2017). Mastery motivation and its relation with the cognitional flexibility for university students. Unbublished master Al-Qadisiyah university-Iraq. [Arabic]

Yazdi, A., Farahi, M., Farahi, M., \& Hosseini, J. (2018). Emotional Intelligence and its role in Cognitive Flexibility of Children with and without Attention Deficit Hyperactivity Disorder. Anales De Psicología/Annals of Psychology, 34(2), 299-304. https://doi.org/10.6018/analesps.34.2.283771

Yilmaz, M. (2009). The effects of an emotional intelligence skills training program on the consistent anger levels of Turkish university students. Social Behavior and Personality: An International Journal, 37(4), 565-576. https://doi.org/10.2224/sbp.2009.37.4.565

\section{Copyright Disclaimer}

Copyright for this article is retained by the author(s), with first publication rights granted to the journal.

This is an open-access article distributed under the terms and conditions of the Creative Commons Attribution license (http://creativecommons.org/licenses/by/3.0/). 